\title{
Biopsy pathology of acquired immune deficiency syndrome (AIDS)
}

\author{
A W BOYLSTON,* H T COOK, N D FRANCIS, R D GOLDIN \\ From the Department of Pathology, St Mary's Hospital Medical School, London
}

SUMMARY Between January 1982 and May 1986279 biopsy specimens from 82 patients with acquired immune deficiency syndrome (AIDS) were examined. A wide variety of infectious conditions were diagnosed, the commonest being Pneumocystis pneumonia $(n=36)$, cytomegalovirus $(n=21)$, a variety of fungi $(n=8)$, mycobacteria $(n=7)$. Kaposi's sarcoma was the commonest tumour $(n=40)$, and there were two cases of extranodal lymphoma.

Striking features were the unusual sites of disease and the occasional paucity of organisms.

The acquired immune deficiency syndrome (AIDS) is one of the manifestations of infection with a human retrovirus that has been given at least four names. It is known variously as lymphadenopathy associated virus (LAV), human T lymphocytotrophic virus type III (HTLV III), AIDS related virus (ARV), or human immunodeficiency virus (HIV). ${ }^{12}$ As defined by the Centre for Disease Control (CDC) in Atlanta, Geogia, the syndrome is the appearance of Kaposi's sarcoma or opportunistic infection in the presence of serological evidence of infection by the causative virus. ${ }^{34}$ It has long been apparent that AIDS is not synonymous with HIV infection and that many patients infected by this virus are healthy or have less devastating symptoms, such as persistent generalised lymphadenopathy, which are sometimes lumped together as the "AIDS related complex" or "minor AIDS". 5

This paper describes the biopsy pathology of a group of 100 consecutive patients with AIDS seen in one hospital between 1982 and mid 1986. Only patients who fulfilled the CDC criteria for the full diagnosis of AIDS were included. The study covers about $30 \%$ of the registered patients with AIDS in the United Kingdom during the study period.

At present AIDS is largely confined to subjects in certain clearly defined risk groups, particularly male homosexuals, haemophiliacs, and users of intravenous drugs. ${ }^{3}$ Outside western Europe and North America, however, the syndrome is common in both sexes, and evidence of probable heterosexual transmission is abundant. ${ }^{67}$ This means that AIDS may occur in migrants or visitors from areas with a different distribution of the disease. It may eventually

Accepted for publication 16 September 1986 spread into the general population of the United Kingdom as well. Thus all surgical pathologists may eventually have to deal with biopsy specimens from those with AIDS, and in at least some instances the diagnosis may not have been suspected on clinical grounds. While most of the diagnoses that were made in our patients are familiar to pathologists in centres with transplantation units or haematological oncology departments, they are not common outside these specialised centres.

The purpose of this report is to outline the spectrum of unusual diagnoses encountered and to indicate that in many instances the appearances differ from those found in classical reference works.

\section{Material and methods}

One hundred patients with AIDS were seen in this hospital during the interval 1982 to mid May 1986. Of these, 82 had at least one tissue biopsy. The 19 patients who did not have biopsies were diagnosed as having AIDS on the basis of characteristic clinical or radiological signs of processes such as cerebral toxoplasma abscess $(n=2)$ or cytomegalovirus (CMV) retinopathy $(n=2)$ or both. In addition, 11 patients with oral or oesophageal candidiasis did not have a biopsy. Three patients had Pneumocystis carinii pneumonia and one patient had cryptosporidium infection, which had been diagnosed at another hospital; the biopsy material was not available for review. A total of 279 biopsy specimens were available for this study. All the specimens from all the patients were included in this study.

Specimens from patients suspected of having AIDS were received in appropriately packaged $10 \%$ formol saline, with a biohazard warning label. They were 
fixed for a minimum of 12 hours, except for urgent bronchial biopsy specimens, which were fixed for one hour at $37^{\circ} \mathrm{C}$. They were processed and embedded by standard methods, cut, and stained as described below.

\section{LUNG}

These were sectioned at a minimum of three levels and stained with haematoxylin and eosin, periodic acid Schiff, Ziehl-Neelsen and Grocott's methenamine silver. The urgent bronchial biopsy specimens were rapidly processed so that three levels stained with Grocott's methenamine silver were available for examination within five hours of receiving the biopsy.

GUT

These were sectioned at a minimum of three levels and stained with haematoxylin and eosin, periodic acid Schiff, Ziehl-Neelsen and May-GrünwaldGiemsa.

\section{SKIN}

These were sectioned at a minimum of three levels and stained with haematoxylin and eosin, periodic acid Schiff, Ziehl-Neelsen and Grocott's methenamine silver.

\section{LIVER}

These were serially sectioned and stained with haematoxylin and eosin, periodic acid Schiff with diastase, silver impregnation for reticulin, iron van Gieson, Ziehl-Neelsen, Masson's trichrome, and Gomori's aldehyde fuchsin.

\section{LYMPH NODES}

These were serially sectioned and stained with haematoxylin and eosin, periodic acid Schiff, reticulin, May-Grünwald-Giemsa and methyl green pyronin.

\section{OTHER SPECIMENS}

These were initially stained with haematoxylin and eosin and other stains, as indicated.

\section{Results}

All but one of the patients were male and their ages ranged from 19 to 54 years at the time of diagnosis. Table 1 lists all the sites from which the biopsy specimens were obtained. In tables 2-6 these are further analysed by site and diagnosis. Figs 1 to 7 show the histological findings in different infections.

Table 1 Sites of biopsies obtained from patients with AIDS

\begin{tabular}{llc}
\hline Site & No of patients & No of biopsies \\
\hline All & 82 & 279 \\
Skin & 35 & 55 \\
Respiratory tract & 56 & 92 \\
Gastrointestinal tract & 46 & 84 \\
Liver & 16 & 21 \\
Lymphoreticular & 18 & 23 \\
Other & 4 & 4 \\
\hline
\end{tabular}

Table 2 Skin biopsy diagnoses in patients with AIDS

\begin{tabular}{llc}
\hline Diagnoses & No of patients & No of biopsies \\
\hline Kaposi's sarcoma & 25 & 33 \\
Fungi* & 4 & 4 \\
Vasculitis & 10 & 11 \\
Other & 5 & $8 \dagger$
\end{tabular}

*Cryptococcus neoformans (figs $5 \mathrm{a}$ and $5 \mathrm{~b}$ ) and histoplasma capsulatum (figs $6 \mathrm{a}$ and $6 \mathrm{~b}$ ). In two cases the type of fungus could not be identified.

†One molluscum contagiosum, one dermatofibroma, one naevus, one milia, two acne, and two abscesses.

Table 3 Diagnoses on respiratory tract biopsy specimens in patients with AIDS

\begin{tabular}{lrc}
\hline Diagnoses & No of patients & No of biopsies \\
\hline Pneumocystis carinii & 28 & 36 \\
Fungi & 2 & 2 \\
Cytomegalovirus & 4 & 5 \\
Mycobacteria & 4 & 4 \\
Acute bacterial & 3 & 3 \\
pneumonia & 22 & 40 \\
Non-specific & 5 & $6^{*}$ \\
Other & & \\
\hline
\end{tabular}

*One each of acute bronchitis, Kaposi's sarcoma, laryngeal dysplasia, nasal papilloma, and two of malaria.

Table 4 Gastrointestinal tract biopsy specimens from patients with AIDS

\begin{tabular}{|c|c|c|}
\hline Diagnoses & No of patients & No of biopsies \\
\hline \multicolumn{3}{|l|}{ Mouth and pharynx: } \\
\hline Kaposi's sarcoma & 2 & 2 \\
\hline Lymphoma & 1 & 1 \\
\hline Non-specific & 2 & 4 \\
\hline \multicolumn{3}{|l|}{ Oesophagus and stomach: } \\
\hline Cytomegalovirus & 2 & 3 \\
\hline Kaposi's sarcoma & $\overline{1}$ & 1 \\
\hline Candida & 1 & $i$ \\
\hline Non-specific & 2 & 4 \\
\hline \multicolumn{3}{|l|}{ Small bowel: } \\
\hline Cryptosporidium & 1 & 1 \\
\hline Mycobacterium & $i$ & i \\
\hline Normal & 2 & 2 \\
\hline \multicolumn{3}{|l|}{ Colon, rectum, and anus: } \\
\hline Cytomegalovirus* & 8 & 13 \\
\hline Herpes* & 2 & 2 \\
\hline Mycobacterium & 1 & 1 \\
\hline or both & 30 & 48 \\
\hline Kaposi's sarcoma & 1 & 2 \\
\hline Lymphoma & 1 & 1 \\
\hline Abscess & 1 & 1 \\
\hline
\end{tabular}

*Illustrated in fig 7a. 
Table 5 Liver biopsy specimens from patients with AIDS

\begin{tabular}{lll}
\hline Diagnoses & No of patients & No of biopsies \\
\hline Acute viral hepatitis & 5 & 5 \\
Non-specific hepatitis & 3 & 3 \\
Cytomegalovirus & 3 & 4 \\
Granulomas & 1 & 2 \\
Mycobacterium & 1 & 1 \\
Cirrhosis & 1 & 1 \\
Fatty infiltration & 2 & 2 \\
Malaria & 1 & 1 \\
Histoplasma & 1 & 1 \\
Peliosis & 1 & 2 \\
Normal & 1 & 1 \\
\hline
\end{tabular}

\section{Discussion}

In our series $82 \%$ of patients had at least one tissue biopsy, and the average number of biopsies was 3.4 per patient. A wide range of variation was disguised by these figures; one patient had had 13 biopsies during a long and complex course.
Table 6 Biopsy diagnoses of lymphoreticular system in patients with AIDS

\begin{tabular}{lll}
\hline Diagnoses & No of patients & No of biopsies \\
\hline Lymph nodes: & & \\
$\quad$ Follicular hyperplasia & 6 & 6 \\
$\begin{array}{l}\text { Lymphocyte depleted } \\
\text { Castleman's disease }\end{array}$ & 4 & 4 \\
Kaposi's sarcoma & 1 & 1 \\
Mycobacteria & 1 & 1 \\
Bone marrow: & & 1 \\
$\quad$ Normal & 6 & \\
$\quad$ Non-specific & 4 & 4 \\
\hline
\end{tabular}

Kaposi's sarcoma in patients with AIDS has characteristic appearances that have been well described. ${ }^{89}$ While necropsy studies suggest that widespread dissemination of Kaposi's sarcoma is common, ${ }^{10}$ systemic disease was found in biopsy specimens from only four of 28 patients, and in these patients previous skin biopsies showing Kaposi's sar-

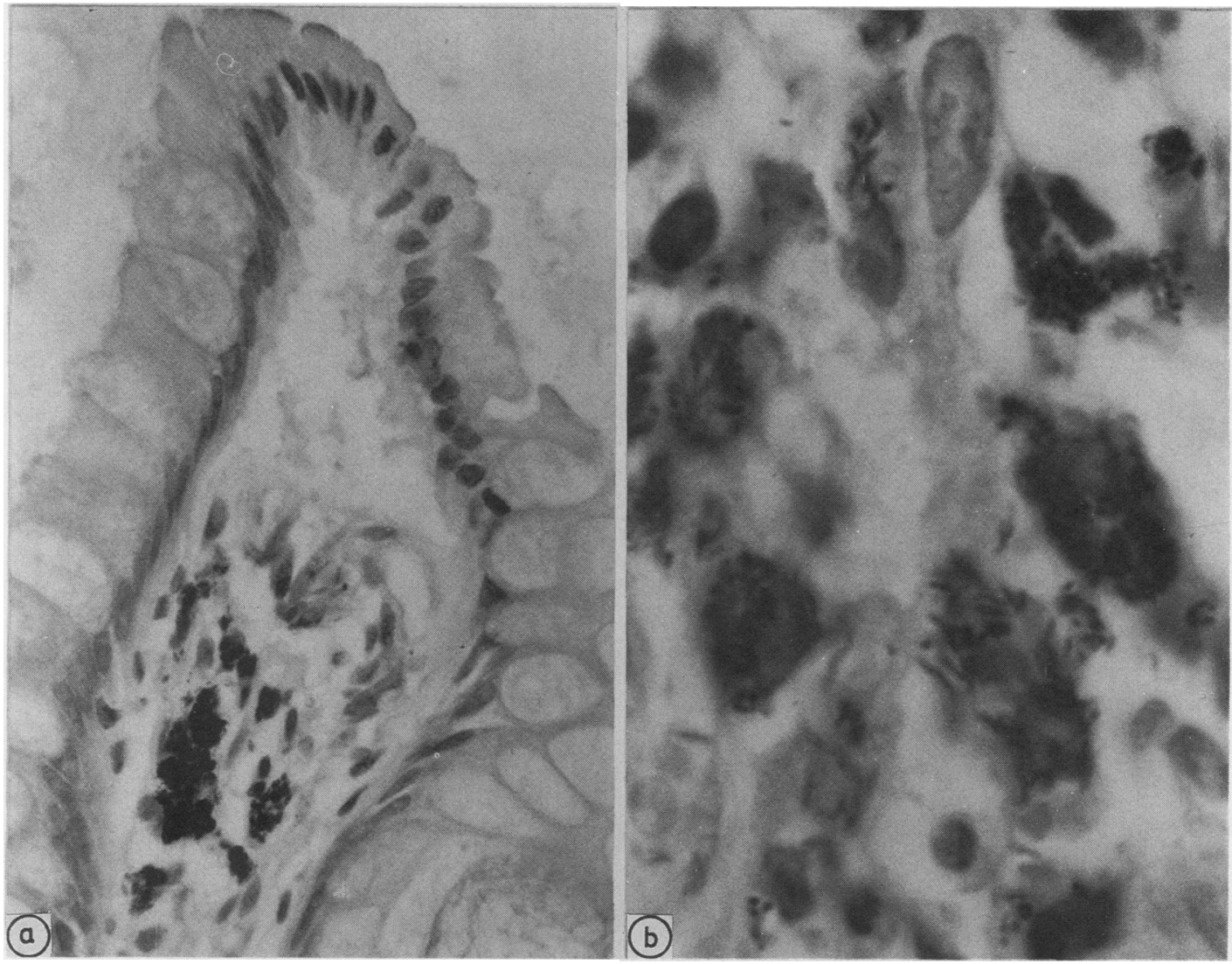

Fig la Rectal mucosal biopsy specimen showing mononuclear cells filled with periodic acid Schiff positive material. $\times 400$.

Fig 1b Acid fast intracellular organisms in mononuclear cells shown in fig Ia. (Ziehl-Neelsen stain.) $\times 1300$. 


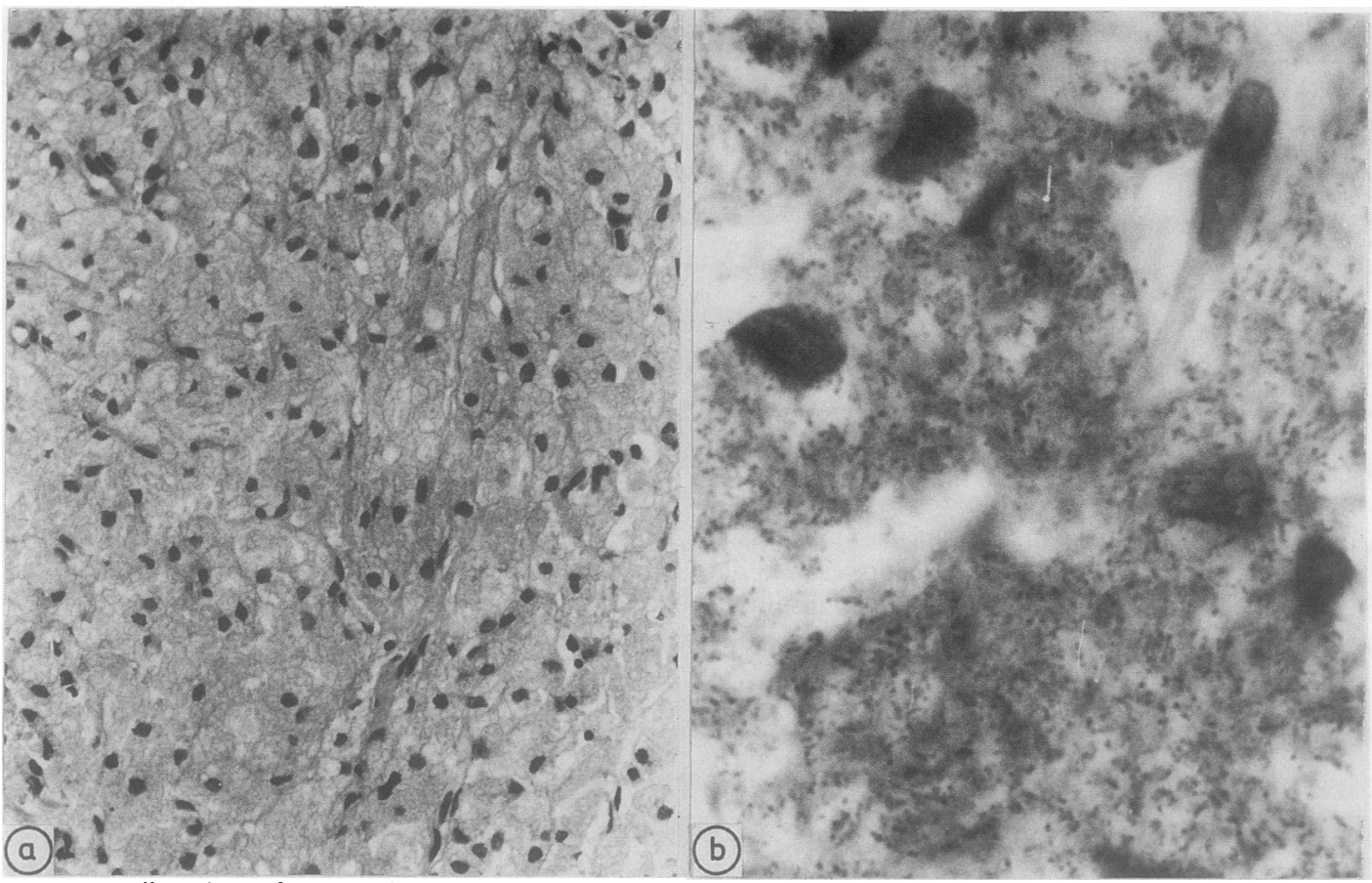

Fig 2a Diffuse sheet of mononuclear cells obtained by needle aspiration of abdominal mass. (Haematoxylin and eosin.) $\times 250$.

Fig $2 \mathrm{~b}$ Intracellular acid fast organisms in cytoplasm of cells shown in fig $2 a$. (Ziehl-Neelsen.) $\times 1000$.

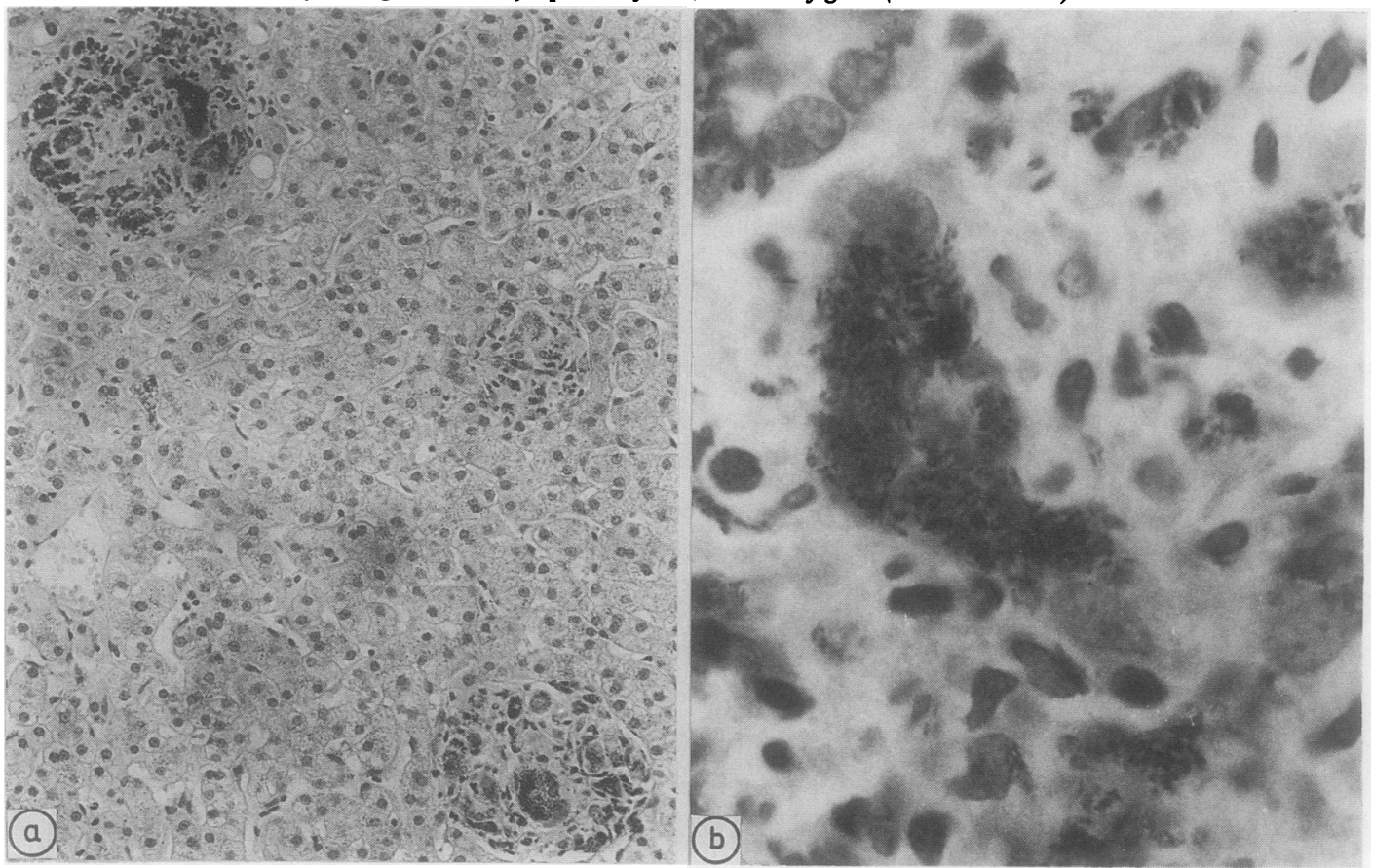

Fig 3a Liver biopsy specimen with three non-caseating granulomas containing granular Ziehl-Neelsen positive material. $\times 125$.

Fig 3b Ziehl-Neelsen stain showing numerous acid fast bacilli in granuloma of fig $3 a . \times 1000$. 


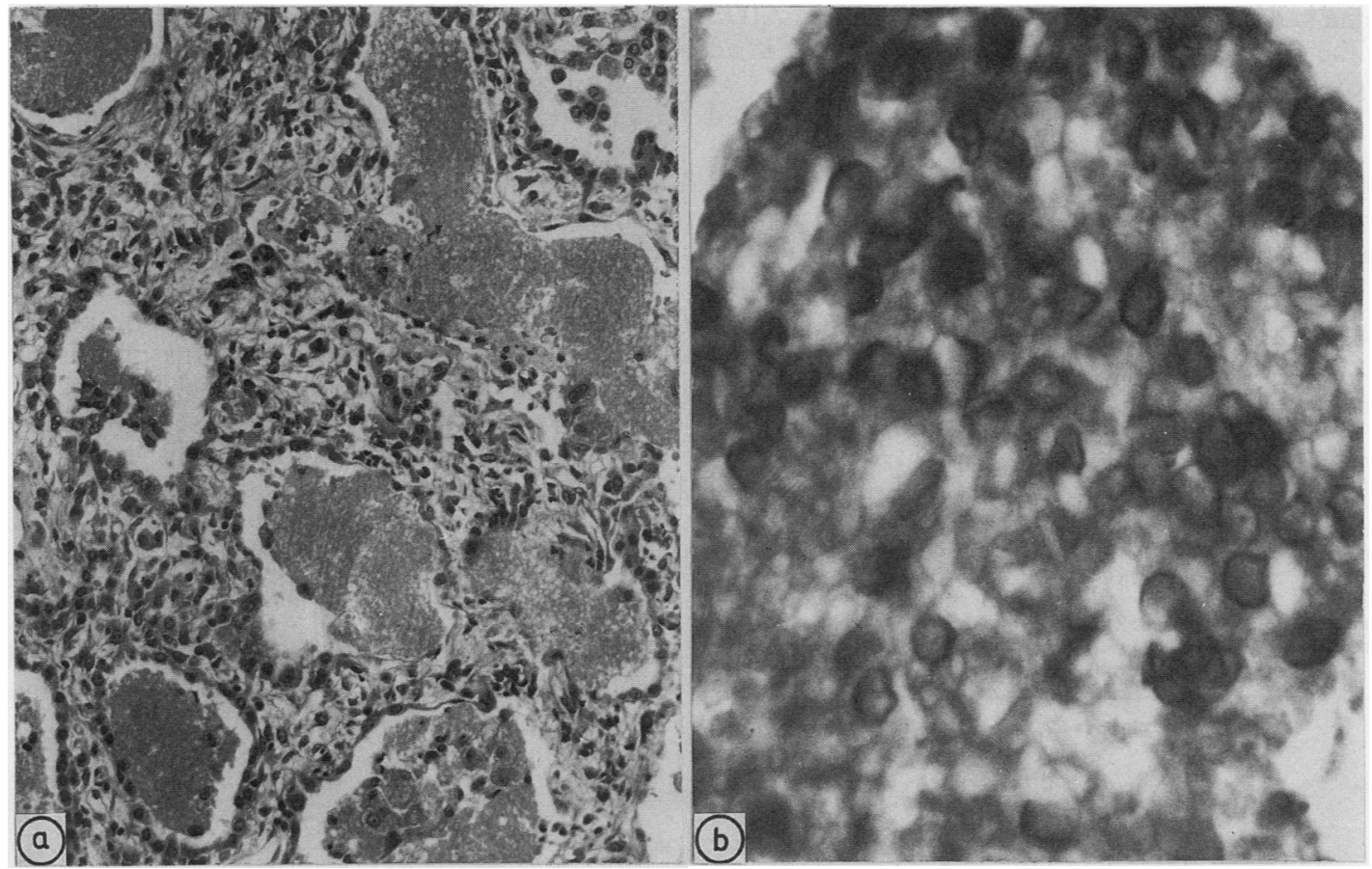

Fig 4a Lung biopsy specimens showing amorphous granular periodic acid Schiff positive material in alveolar spaces. $\times 250$.

Fig 4b Cysts of Pneumocystis carinii in alveolar exudate shown in fig 4a. (Grocott.) $\times 1000$.

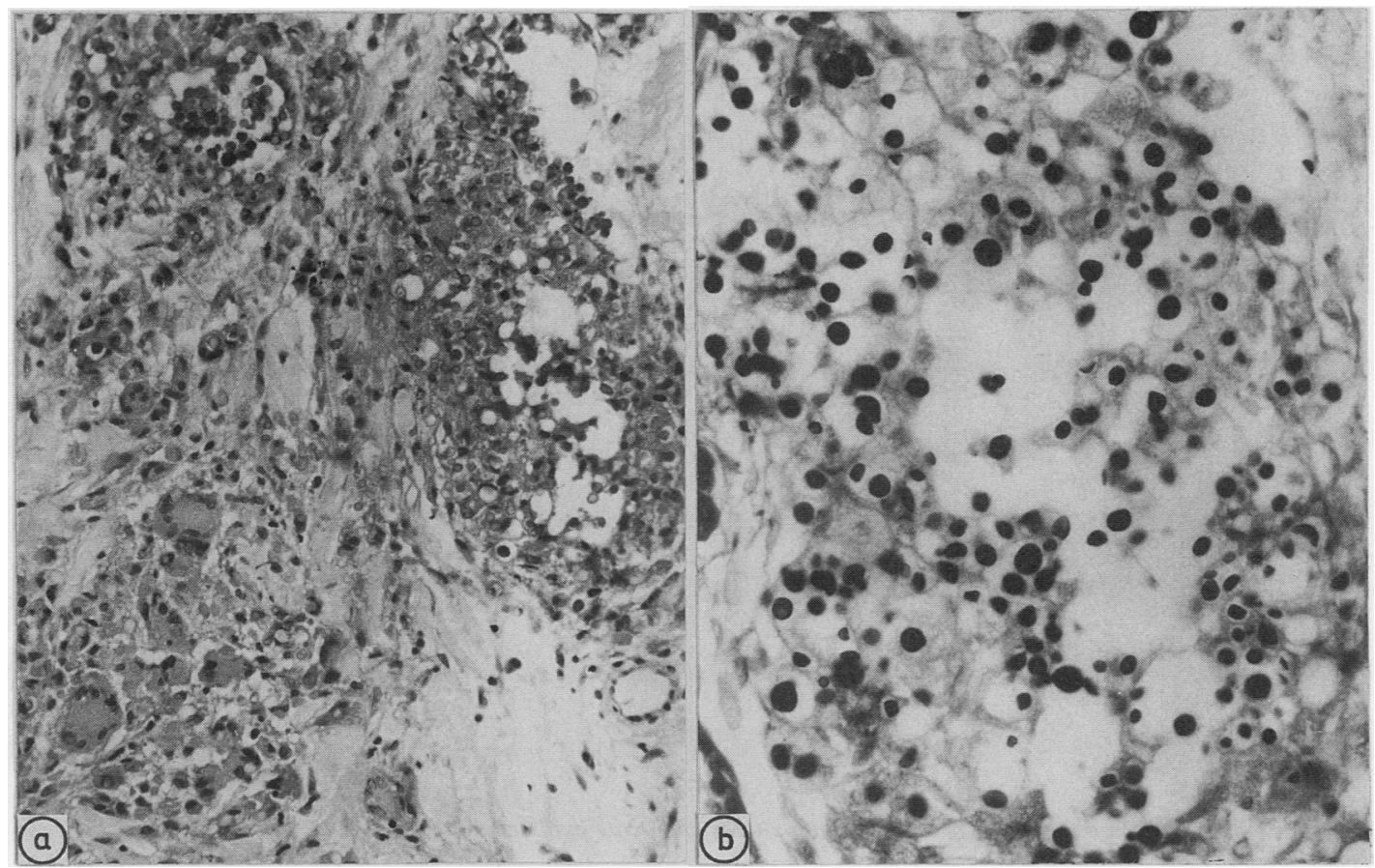

Fig 5a Skin biopsy specimen showing both granulomatous and mucoid types of cryptococcal infection. (Haematoxylin and eosin.) $\times 250$.

Fig 5b Cryptococcal organisms shown in mucoid areas of fig 5a. (Grocott.) $\times 400$. 
coma had been obtained. Thus presentation of AIDS as the unexpected finding of Kaposi's sarcoma in an organ other than the skin was rare.

Fourteen different micro-organisms were identified in biopsy material. The presence of more than one organism in a biopsy specimen was not uncommon, and in one specimen four separate infections were identified. Table 7 summarises the range of multiple infections in single biopsy specimens. Because of the

Table 7 Multiple infectious agents seen in tissue biopsies

\begin{tabular}{ll}
\hline Site & Organisms identified \\
\hline Lung & Pneumocystis carinii pneumonia, CMV \\
Anal skin & Herpes, CMV \\
Lung & Pneumocystis carinii pneumonia, Cryptococcus \\
Lung & Pneumocystis carinii pneumonia, CMV \\
Lung & Pneumocystis carinii pneumonia, AFB, CMV, \\
Lung & malaria \\
Lung & Pneumocystis carinii pneumonia, CMV \\
Lung & Pneumocystis carinii pneumonia, AFB \\
& Pneumocystis carinii pneumonia, acute \\
& pneumonia with Gram positive diplococci \\
\hline
\end{tabular}

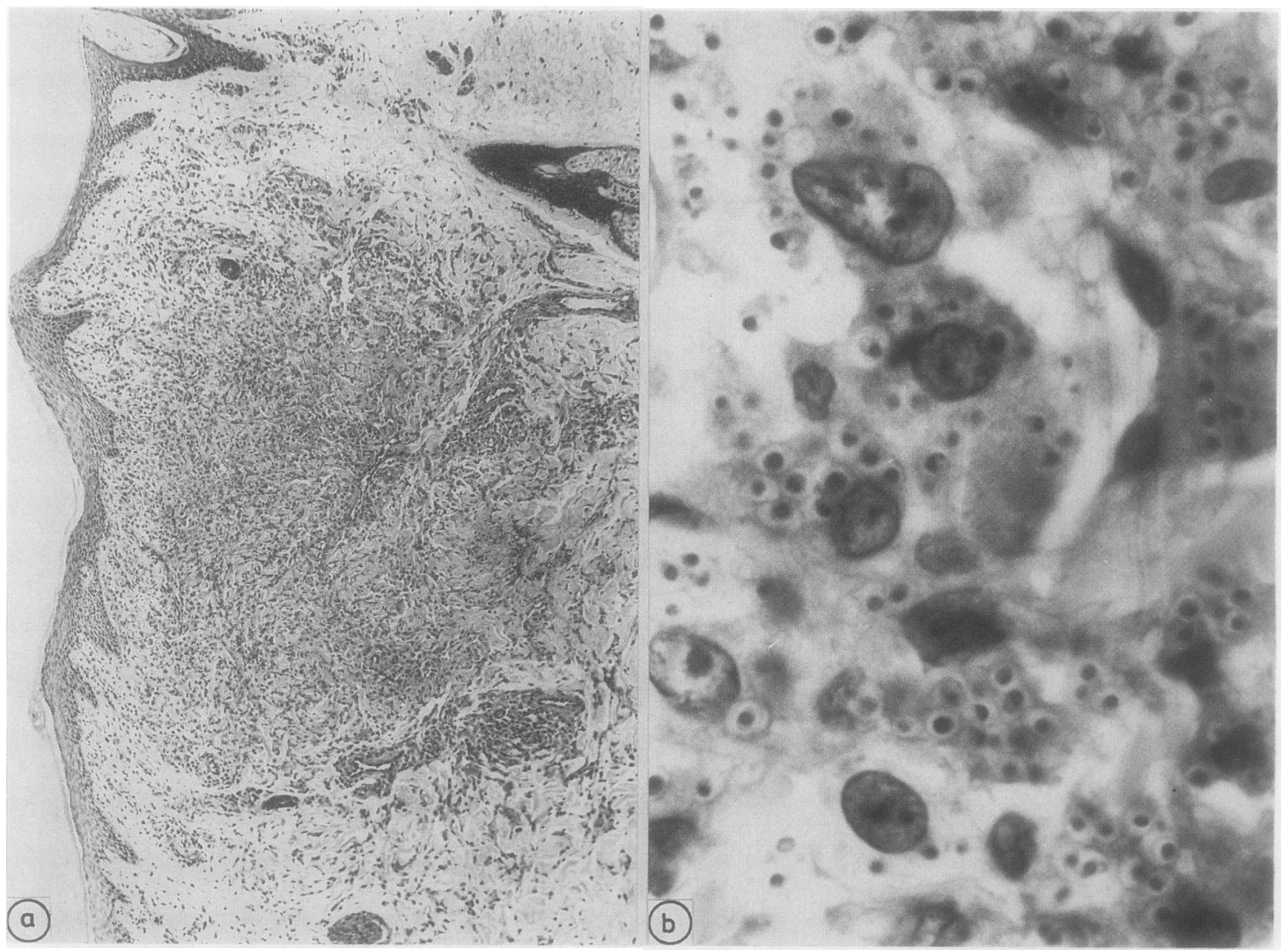

Fig 6a Skin biopsy specimen showing cutaneous inflammatory infiltrate in disseminated histoplasmosis. (Haematoxylin and eosin.) $\times 40$.

Fig 6b Histoplasma organisms intracellular and extracellular from lesion shown in fig 6a. (Periodic acid Schiff.) $\times 1000$. diverse infections encountered, we evolved a protocol for the stains routinely used on biopsy specimens from various sites.

In patients with AIDS some of the infections have appearences different from those commonly encountered. This is particularly true of mycobacteria and cytomegalovirus (CMV). In most of our biopsy specimens in which mycobacteria were identified the organisms were present in large numbers inside macrophages. The appearances varied from a single mycobacteria stuffed cell in the lamina propria of a large bowel biopsy specimen, which mimicked a muciphage in the periodic acid Schiff stain (figs la and b) to a solid sheet of bacteria filled cells replacing an abdominal lymph node (figs $2 \mathrm{a}$ and $\mathrm{b}$ ). ${ }^{11}$ These specimens resembled the appearances seen in lepromatous leprosy. Caseating granulomas were not found in our patients, probably reflecting their immunodeficiency (figs $3 a$ and $b$ ).

Cytomegalovirus infection was most commonly identified by the presence of a single cell containing 


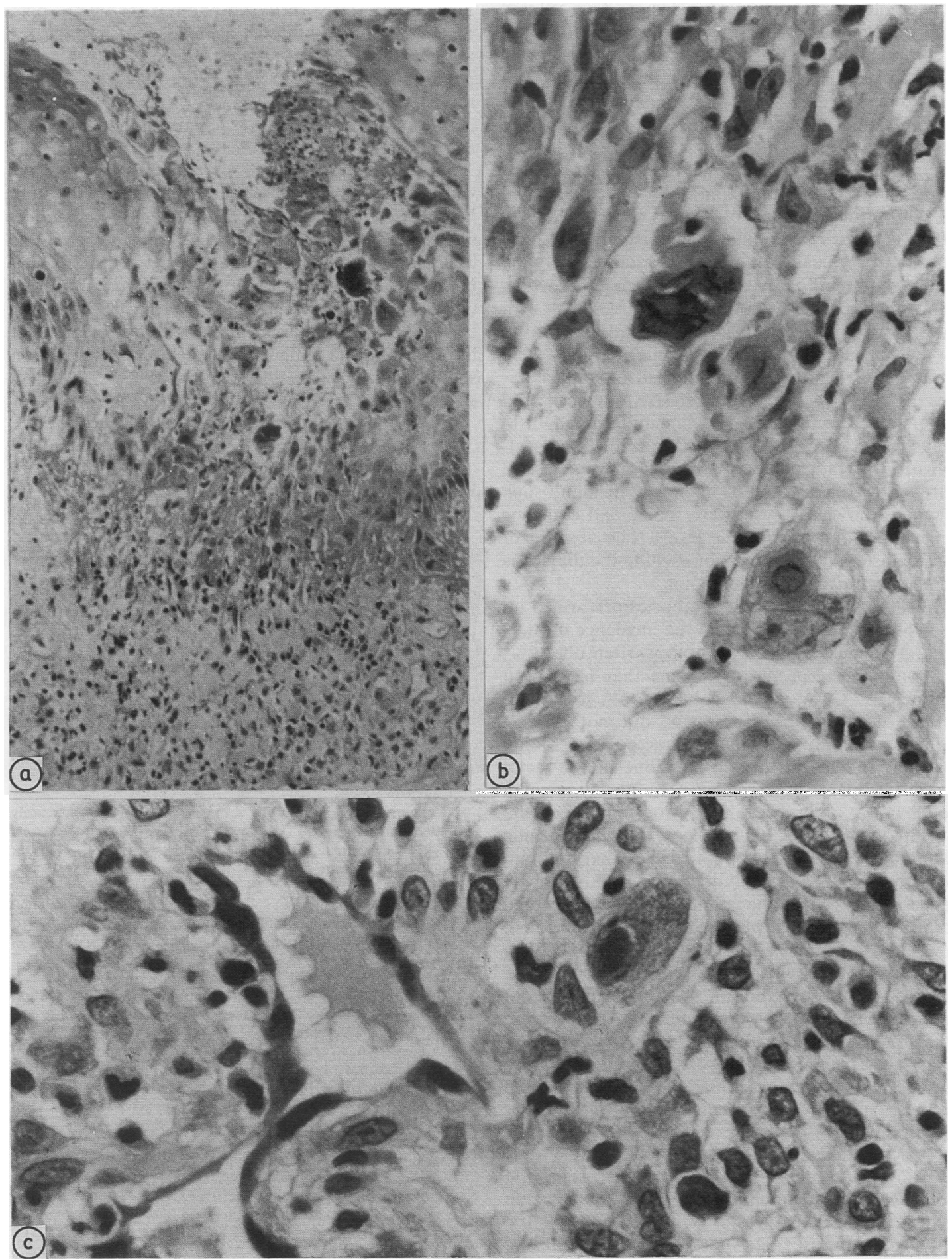

Fig 7a Ulcerated perianal skin and underlying inflammatory infiltrate. (Haematoxylin and eosin.) $\times 125$.

Fig $7 \mathrm{~b}$ Multinucleated squamous cells characteristic of herpes infection from ulcerated lesion in fig $7 a$. (Haematoxylin and eosin.) $\times 400$.

Fig 7c Mononuclear cell containing intranuclear inclusion body characteristic of CMV in inflammatory infiltrate shown in fig 7a. (Haematoxylin and eosin.) $\times 530$. 
the characteristic intranuclear inclusion. This cell was usually not related to small blood vessel endothelium, as commonly described, but occurred anywhere. ${ }^{12}$ In particular, cells with the appearances of luminal epithelium or lying free in the lamina propria of the gastrointestinal tract mucosa were found. Cells resembling either monocytes or desquamated pneumocytes containing inclusions were seen in lung biopsy specimens. We did not observe evidence of CMV infection in lesions of Kaposi's sarcoma.

Pneumocystis carinii pneumonia also showed both typical and atypical features. ${ }^{13}$ Characteristically the alveoli contained foamy eosinophilic material, which was strongly periodic acid Schiff positive (fig 4a). In most cases large clusters of cysts, appearing as round or oval concave discs with refractile margins, were seen in the Grocott's methenamine silver stained sections (fig 4b). They were similar in size to red cells and in overstained sections may be difficult to distinguish. The use of a control positive section stained in parallel with the biopsy specimen was a very useful approach to the successful diagnosis. In many such specimens, however, cysts were sparse and could be seen in only one of multiple levels. The absence of typical clusters of cysts did not exclude the diagnosis of Pneumocystis carinii pneumonia.

The large numbers of rectal biopsies performed on this group of patients reflected the incidence of diarrhoea. The cause of this symptom is often obscure. ${ }^{3}$ The commonest specific organisms that have been identified are CMV and mycobacteria. A large proportion of the biopsy specimens did not yield a specific agent; only 16 of the 68 large bowel and anal specimens showed an organism. None of the rectal biopsy specimens, however, was completely normal. The changes observed ranged from mild oedema associated with a slight increase in chronic inflammatory cells and lymphoid follicle involution to intense oedema, superficial ulceration, and an apparent decrease in cells in the lamina propria. Occasional necrotic glands and crypt abscesses were also noted. An interesting observation was that none of these specimens showed evidence of spirochaetosis.

The changes observed in the small number of lymph nodes examined were similar to those seen in other studies. ${ }^{14}$ The appearances ranged from follicular hyperplasia through follicular involution to lymphocyte depletion. Although it has been suggested that these changes can be used to generate a three tier staging scheme for AIDS lymphadenopathy, our experience is that the changes overlap and one node may show areas of both follicular hyperplasia and involution. It is worth emphasising that there are no specific diagnostic features of AIDS in lymph nodes, apart from Kaposi's sarcoma or an opportunistic organism.

There were two lymphomas, and both were diffuse high grade large cell lymphomas showing plasmacytoid differentiation arising in extranodal sites. Similar tumours have been observed by others in patients with AIDS. ${ }^{15}$ The atypical presentation of these tumours, one as an ulcerating lesion on the neck, and the other as an anal fistula, should be emphasised.

Our experience of the biopsy pathology of patients with AIDS closely resembles that reported from North America. ${ }^{16}$ All biopsy specimens from patients with suspected AIDS should be examined at multiple levels and routine special stains used. This will pick up small numbers of organisms that may occur in unexpected sites and may produce atypical histological and clinical pictures. The possibility of multiple infections in one patient or a single biopsy specimen should always be considered.

\section{References}

1 Coffin J, Harre A, Levy JA, etal. Human immunodeficiency virus. Science 1986;232:697.

2 Marx JL. "AIDS virus has new name-perhaps. [Editorial]. Science 1986;232:699-700.

3 Fauci AS, Macher AM, Longo DL, et al. Acquired immunodeficiency syndrome: epidemiologic, clinical, immunologic and therapeutic considerations. Ann Intern Med 1984;100:92-106.

4 Centre for Disease Control. Update on acquired immune deficiency syndrome. $M M W R$ 1982;31:507-8.

5 Marthur-Wagh V, Enlow RW, Spigland Z, et al. Longitudinal study of persistent generalized lymphadenopathy in homosexual men: relation to acquired immune deficiency syndrome. Lancet 1984; i: 1033-8.

6 Harris C, Small CB, Klein RS, et al. Immunodeficiency in sexual partners of men with the acquired immune deficiency syndrome. New Engl J Med 1983;308:1181-4.

7 Barnes DM. AIDS research in new phase. Science 1986;233:282-3.

8 Francis N, Parkin J, Weber J, Boylston A. Kaposi's sarcoma in acquired immune deficiency syndrome (AIDS). J Clin Pathol 1986;39:469-74.

9 Gottleib GJ, Ackerman AB. Kaposi's sarcoma: an extensively disseminated form in young homosexual men. Hum Pathol 1982;13:882-92.

10 Niedt GW, Schinella RA. Acquired immune deficiency syndrome. Arch Pathol Lab Med 1985;109:727-34.

11 Gillin JS, Urmacher C, West R, Shike M. Disseminated Mycobacterium avium-intracellulare infection in the acquired immune deficiency syndrome mimicking Whipples disease. Gastroenterology 1983;85:1187-91.

12 Meiselman MS, Cello JP, Margaretten W. Cytomegalovirus colitis. Report of the clinical, endoscopic and pathological findings in two patients with the acquired immune deficiency syndrome. Gastroenterology 1985;88:171-5.

13 Marchevsky A, Rosen MJ, Chrystal G, Kleinerman J. Pulmonary complications of the acquired immune deficiency syndrome. Hum Pathol 1985;16:659-70.

14 Ewing EP, Chandler FW, Spira TJ, Brynes RK, Chan WC. Primary lymph node pathology in AIDS and AIDS related Lymphadenopathy. Arch Pathol Lab Med 1985;109:977-81.

15 Ioachim HL, Cooper MC, Hellman GC. Lymphomas in men at high risk for AIDS. Cancer 1985;56:2831-42.

16 Amberson JB, DiCarlo EF, Metroka CE, Koizumi JH, Mouradian JA. Diagnostic pathology in the acquired immunodeficiency syndrome. Arch Pathol Lab Med 1985;109:345-51.

Requests for reprints to: Dr AW Boylston, Department of Pathology, St Mary's Hospital Medical School, London W12, England. 